\title{
Technical Evaluation of Temporal Groundwater Monitoring Variability in MW66 and Nearby Wells, Paducah Gaseous Diffusion Plant
}

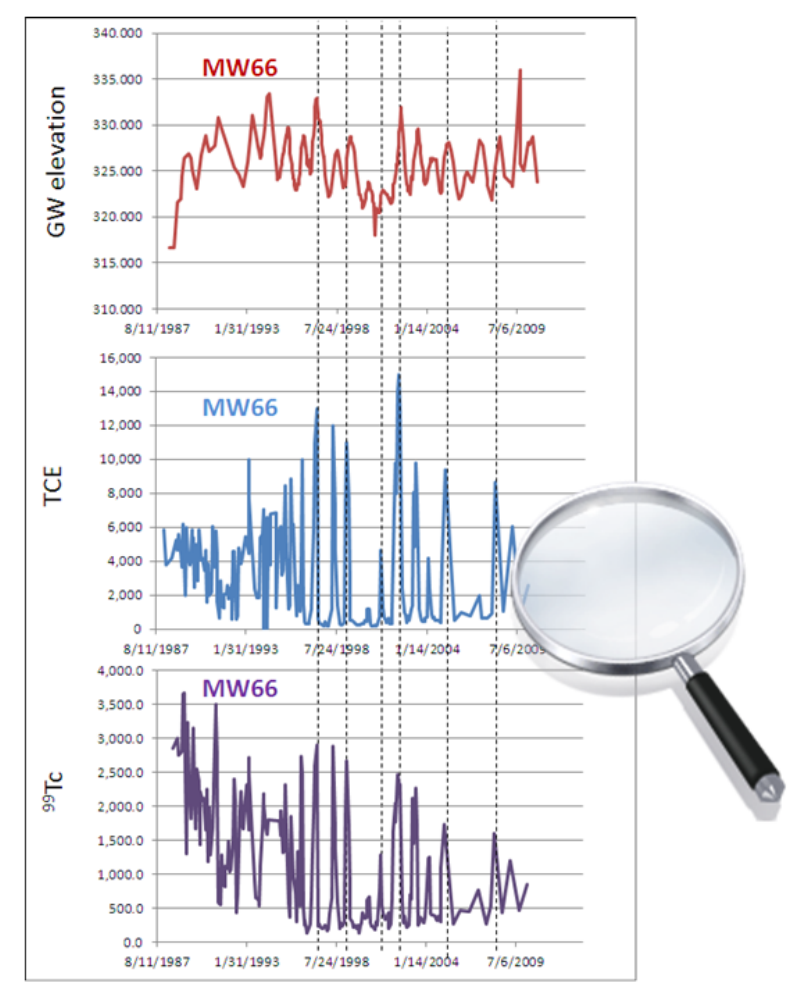

August 2012

Prepared for: The U.S. Department of Energy Office of Environmental Management Soil and Groundwater Remediation Technology (EM12), Washington, DC

Prepared by: The DOE EM Center for Sustainable Groundwater and Soil Solutions, Savannah River National Laboratory, Aiken SC

Technical content and coordination for this effort was provided by the Savannah River National Laboratory in conjunction with Contract No. DE-AC09-08SR22470 with the U.S. Department of Energy. 

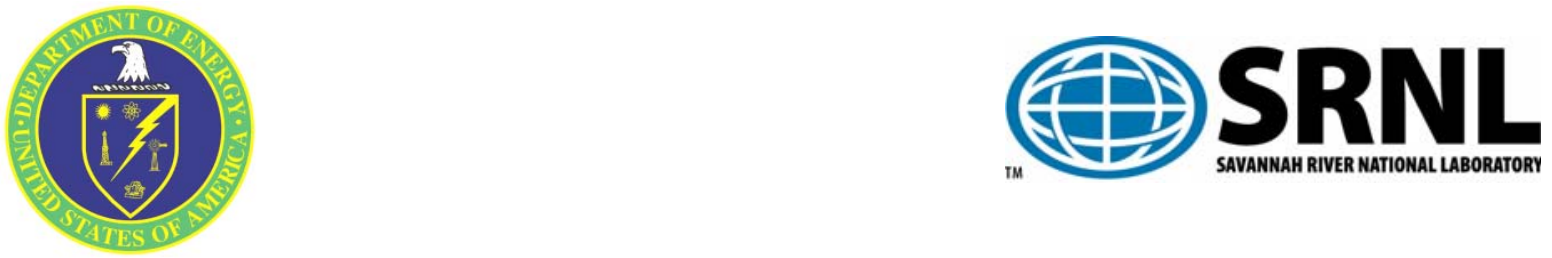

\title{
DISCLAIMER
}

This work was prepared under an agreement with and funded by the U.S. Government. While the authors have taken care in the preparation of this report, neither the U. S. Government or its employees, nor any of its contractors, subcontractors or their employees, makes any express or implied: 1. warranty or assumes any legal liability for the accuracy, completeness, or for the use or results of such use of any information, product, or process disclosed; or 2. representation that such use or results of such use would not infringe privately owned rights; or 3. endorsement or recommendation of any specifically identified commercial product, process, or service. Any views and opinions of authors expressed in this work do not necessarily state or reflect those of the United States Government, or its contractors, or subcontractors.

\author{
Printed in the United States of America \\ Prepared For \\ U.S. Department of Energy \\ Office of Engineering and Technology
}




\title{
Technical Evaluation of Temporal Groundwater Monitoring Variability in MW66 and Nearby Wells, Paducah Gaseous Diffusion Plant
}

\author{
Authors: \\ Brian B. Looney (Savannah River National Laboratory) \\ Carol A. Eddy-Dilek (Savannah River National Laboratory)
}

August 2012

Technical content and coordination for this effort was provided by the Savannah River National Laboratory in conjunction with Contract No. DE-AC09-08SR22470 with the U.S. Department of Energy. 
SRNL-STI-2012-00513 rev. 1

\{Blank page $\}$ 


\section{Table of Contents}

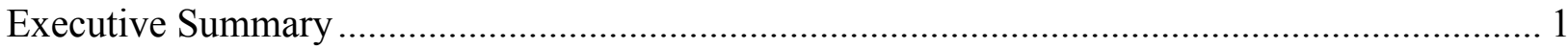

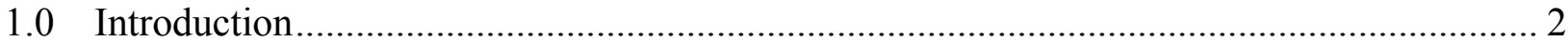

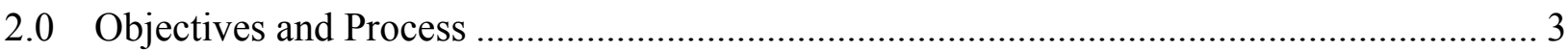

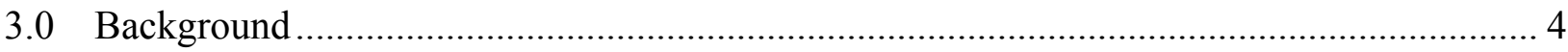

Description of Sitewide Soil and Groundwater ............................................................... 4

Previous Evaluation of Temporal Concentrations in MW66 and Nearby Wells................... 5

Follow-up Studies and Updated Information.................................................................. 5

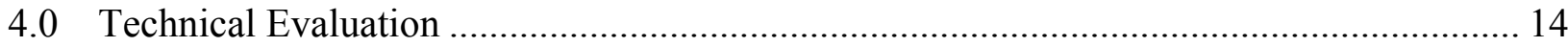

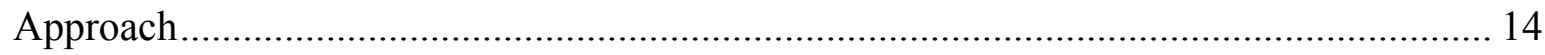

Refined Conceptual Model - “A Hypothesis”.................................................................. 14

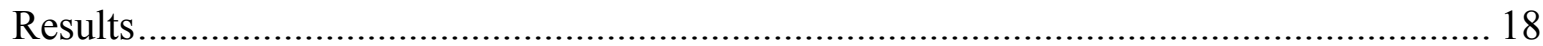

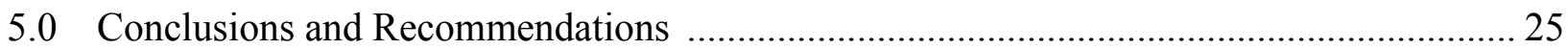

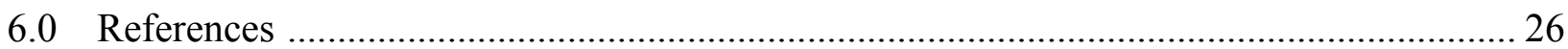

\section{List of Figures}

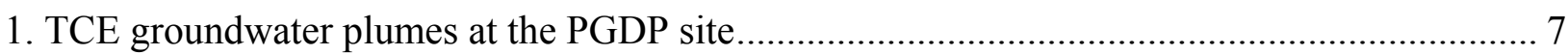

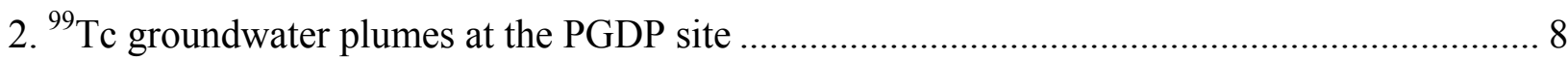

3. Location of the various Burial Ground SWMUs at PGDP …………….................................. 9

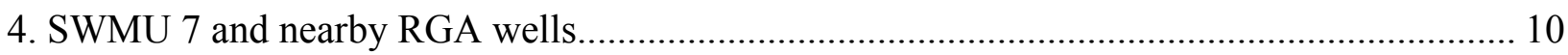

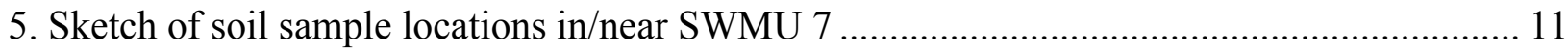

6. Groundwater trends in select monitoring wells in/near SWMU 7 ........................................... 13

7. Sketch of hypothetical plume geometry for a central PGDP scenario...................................... 16

8. Cross sectional contaminant distributions in the UCRS and RGA........................................... 17

9. Temporally registered data: RGA head - TCE - 99Tc in MW66 ………………............ 19-20

10. Temporally registered data: TCE/99TC ratio - TCE - 99Tc in MW66 ................................. 21

11. Temporally registered data: RGA head - TCE in MW66 - monthly rainfall in KY.............. 23

12. Known areas of anthropogenic water releases or of frequently standing water ..................... 24 


\section{Acronyms and Abbreviations}

$\begin{array}{ll}\% & \text { Percent } \\ \text { BGOU } & \text { Burial Ground Operable Unit } \\ \text { DOE } & \text { U.S. Department of Energy } \\ \text { DNAPL } & \text { dense nonaqueous phase liquid } \\ \text { EM-12 } & \text { DOE Office of Soil and Groundwater Remediation } \\ \text { EPA } & \text { U.S. Environmental Protection Agency } \\ \text { EW } & \text { extraction well } \\ \text { Kg } & \text { Kilogram } \\ \text { KRCEE } & \text { Kentucky Research Consortium for Energy and Environment } \\ \text { L } & \text { Liters } \\ \text { m } & \text { meter } \\ \text { Msl } & \text { mean sea level } \\ \mu \text { g/kg } & \text { micrograms of contaminant per Kg of dry soil } \\ \mu \text { g/L } & \text { micrograms of contaminant per liter of water } \\ \text { mg/kg } & \text { milligrams of contaminant per Kg of dry soil } \\ \text { MW } & \text { monitoring well, as in monitoring well 66 (MW66) } \\ \text { NW } & \text { Northwest } \\ \text { pCi/L } & \text { picocuries per liter of water } \\ \text { PGDP } & \text { Portsmouth Gaseous Diffusion Plant } \\ \text { RGA } & \text { Regional Gravel Aquifer } \\ \text { RI } & \text { Remedial Investigation } \\ \text { SI } & \text { Site Investigation } \\ \text { SVE } & \text { Soil Vapor Extraction } \\ \text { SW } & \text { Southwest } \\ \text { SWMU } & \text { Solid Waste Management Unit } \\ 99 \text { Tc } & \text { technetium-99 } \\ \text { TCE } & \text { trichloroethene } \\ \text { TP } & \text { Test pit, as in test pit 5 (TP5) } \\ \text { TCE } & \text { Trichloroethene } \\ \text { UCRS } & \text { Upper Continental Recharge System } \\ \text { WAG } & \text { Waste Area Group } \\ & \end{array}$




\section{Executive Summary}

Evaluation of disposal records, soil data, and spatial/temporal groundwater data from the Paducah Gaseous Diffusion Plant (PGDP) Solid Waste Management Unit (SWMU) 7 suggest that the peak contaminant concentrations measured in monitoring well (MW) 66 result from the influence of the regional PGDP Northwest (NW) Plume. The resulting "weight of evidence" calls into question the role of significant vertical transport from local contaminant sources in SWMU 7 into the regional gravel aquifer. This updated evaluation supports the 2006 conceptualization which suggested the high and low concentrations in MW66 represent different flow conditions (i.e., local versus regional influences). Incorporation of the additional lines of evidence from data collected since 2006 provide a relatively strong basis to link high contaminant concentrations in MW66 (peaks) to the regional "Northwest Plume" and to an upgradient source, specifically, the C-400 Building Area.

The conceptual model was further refined to demonstrate that groundwater and the various contaminant plumes respond to complex site conditions in predictable ways. This type of conceptualization bounds the expected system behavior and supports development of environmental cleanup strategies, providing a basis to support decisions even if it is not feasible to completely characterize all of the "complexities" present in the system. We recommend that the site carefully consider the potential impacts to groundwater and contaminant plume migration as they plan and implement onsite production operations, remediation efforts, and reconfiguration activities. For example, this conceptual model suggests that rerouting drainage water, constructing ponds or basin, reconfiguring cooling water systems, capping sites, decommissioning buildings, fixing (or not fixing) water leaks, and other similar actions will potentially have a "direct" impact on the groundwater contaminant plumes.

Our conclusion that the peak concentrations in MW66 are linked to the regional PGDP NW Plume does not imply that trichloroethene (TCE) is not present in SWMU 7. The available soil and groundwater data indicate that the some of the wastes disposed in this facility contacted and/or were contaminated by TCE. In our assessment, the relatively small amount of TCE associated with SWMU 7 is not contributing statistically detectable TCE to the groundwater and does not represent a significant independent threat to the environment, particularly in an area where remediation and/or management of TCE in the NW plume will be required for an extended timeframe. If determined to be necessary by the PGDP team and regulators, additional TCE characterization or cleanup activities could be performed. Consistent with the limited quantity of TCE in SWMU 7, we identify a range of low cost approaches for such activities (e.g., soil gas surveys for characterization or soil vapor extraction (SVE) for remediation).

We hope that this information is useful to the Paducah team and to their regulators and stakeholders to develop a robust environmental management path to address the groundwater and soil contamination associated with the burial ground areas. 


\subsection{Introduction}

In their 2006 review of groundwater monitoring data from the Regional Gravel Aquifer (RGA) beneath the PGDP, Becker et al (2006) identified and discussed the potential significance of spiking and oscillating contaminant concentrations in monitoring and extraction wells near and downgradient of SWMU 7. They suggested that the periods of high and low concentration of contaminants within a well represent different hydrologic conditions in which the monitoring well was preferentially capturing either local flow lines (i.e., water infiltrating vertically in the vicinity of the well) or regional flow lines (i.e., water flowing horizontally from upgradient). At that time, the reviewers concluded that the high concentration spikes of trichloroethene (TCE) and technetium $99\left({ }^{99} \mathrm{Tc}\right)$ likely represented local sources of contamination that periodically impacted some of the monitoring and extraction wells. Based on these observations, the reviewers recommended additional evaluation of temporal variability and trends in groundwater concentrations throughout PGDP; and specifically for areas with wells that exhibit episodic concentration spikes and other unusual features, the reviewers recommended follow-up assessment to assess the potential for local contaminant sources. Recommended activities included evaluation of historical waste site data for SWMU 7 and other nearby facilities, vadose zone characterization, and continued evaluation of groundwater information over time.

Since 2006, the PGDP team has performed many of the recommended activities near SWMU 7, and the results provide important information to support environmental management decisions. In particular, the more complete information and longer period of record support a more defensible assessment of the potential for regional versus local sources of the observed contaminants in this area.

The updated data supports the 2006 conceptualization that the high and low concentrations represent different flow conditions (i.e., local versus regional influences). However, as described in the following sections, the additional disposal history information, vadose characterization and more detailed evaluation of the groundwater concentrations (long term trends, contaminant ratios, etc.) indicate that the high concentrations are more likely associated with the regional plume and are not indicative of high-strength local sources in SWMU 7. 


\subsection{Objectives and Process}

The overall objective of this work is to evaluate historic and recent groundwater monitoring trends in Monitoring Well 66 (MW66) and adjacent wells to help determine the potential and significance of unidentified local contaminant sources. Recent data supporting this analysis include: site characterization and vadose zone data, historical waste site data for SWMU 7 and other nearby facilities, horizontal and vertical position of the well screen and nearby wells, local geology and geological/contaminant cross sections, location(s) of known or suspect contamination sources, correlation of observed spikes with factors such as weather patterns, rainfall and seasons, response of well concentration to changes in the NW plume pump and treat operation, and various alternative conceptual models related to the observed concentration changes in MW66. The primary deliverable from this work is a short report that provides an independent assessment of:

1) the significance of the various potential contaminant source(s) impacting MW66,

2) identification of the uncertainties associated with the assessment, and

3) recommendations for specific actions/activities to help resolve the uncertainties.

This work was performed as a technical assistance screening activity by Brian Looney (Environmental Engineer) and Carol Eddy-Dilek (Geologist) of the Savannah River National Laboratory. The primary goal of the work is to support the Paducah team and their regulators/stakeholders.

We would like to acknowledge the high level support provided by the PGDP team during this technical evaluation process. In particular, we would like to commend the team for their technical efforts and to recognize the availability and general high quality of the groundwater database and the ability to provide access to our team via the internet (allowing queries of laboratory and field results, generation of maps, and providing well construction information). 


\subsection{Background}

\section{Description of Sitewide Soil and Groundwater}

The groundwater underlying PGDP has been impacted by contaminants released during site operations into the subsurface, principally TCE and ${ }^{99} \mathrm{Tc}$. The predominant source of TCE is near and under Building C-400 and that area is coincident with the highest TCE concentrations. There is also significant ${ }^{99} \mathrm{Tc}$ contamination of groundwater in the C-400 area. Other known and potential sources of contaminants exist at PGDP (e.g., various hazardous and radioactive burial grounds and disposal facilities such as the SWMU 7 and other nearby burial grounds). Currently, a phased active remediation strategy is being implemented to remediate TCE contamination in the subsurface near Building C-400.

The subsurface beneath PGDP has three relevant hydrogeologic zones from top to bottom:

- Upper Continental Recharge System (UCRS), upper $\cong 20 \mathrm{~m}$ consists of fine- to medium-grained sediment;

- Regional Gravel Aquifer (RGA), $5 \mathrm{~m}$ to $10 \mathrm{~m}$ thick, consisting primarily of medium- to coarse-sand and gravel;

- McNairy Formation (McNairy) comprised of relatively less permeable sandy-clay and clay.

These principal zones can be further subdivided based on specific layering and sediment properties. The "water table" ranges in depth from 1 to $5 \mathrm{~m}$, and occurs within the middle to lower UCRS. Note that the elevation of the piezometric surface (water table) in the UCRS is significantly higher than the piezometric surface in the RGA, a further indication of the relatively low permeability of the UCRS and the slow downward movement of water through the UCRS.

Contaminants are typically transported from surface source zones "vertically" through the UCRS into the groundwater, and the resulting dissolved phase plume is laterally transported by groundwater flow in the relatively permeable RGA. There are multiple groundwater plumes underlying PGDP; the most significant plume is the Northwest (NW) Plume. SWMU 7 is located downgradient of C-400 so that the associated monitoring wells for this SWMU could potentially be influenced by the NW Plume and by local inputs/sources (Figures 1 and 2). Note that SWMUs 7 and 30 are two of the eight burial ground areas that are generally located in the upper northwest corner of the PGDP site (Figure 3). Figure 4 is an overhead photographic image of a portion of PGDP annotated to show the approximate locations of SWMU 7, some of the nearby monitoring and extraction wells in the RGA, and the general path of the NW Plume. As shown in Figure 4, a modification to improve the performance of the NW Plume pump and treat system refocused pumping of extraction wells in this area (discontinuing pumping from wells EW230 and EW231 with startup of wells EW 232 and 233 at a higher flow rate) in August 2010. These changes in the remedial campaign are a key factor in the eastward shift in trajectory of the plume, as shown, over the past two years. 


\section{Previous Evaluation of Temporal Concentrations in MW66 and Nearby Wells}

Becker et al. (2006) highlighted the spiking of contaminant concentrations in MW66, MW248 and Extraction Well 230 (EW230). TCE concentrations in EW230 oscillated between a lower range of 3,000 to $5,000 \mu \mathrm{g} / \mathrm{L}$, and a higher range of 15,000 to 40,000 $\mu \mathrm{g} / \mathrm{L}$. The activities of ${ }^{99} \mathrm{Tc}$ in this extraction well exhibited somewhat similar behavior, oscillating between a lower range of 500 to $1,000 \mathrm{pCi} / \mathrm{L}$, and a higher range of 1,000 to $2,000 \mathrm{pCi} / \mathrm{L}$. Similar spikes in contaminant concentrations were noted for some of the nearby monitoring wells located upgradient of EW230, including MW66 and MW248. A preliminary evaluation attributed the significant oscillations to changes in contaminant releases or changes in plume structure "in response to seasonal and climactic variations." Based on several factors, such as the position of the well screen in MW66 in the upper portion of the RGA, the reviewers indicated that the concentration variations "suggest local contaminant sources in this area of the Northwest Plume" and recommended that the PGDP team "evaluate groundwater monitoring trends to more comprehensively ..." using multiple lines of evidence (historical information, vadose zone characterization, and continued interpretation of groundwater concentration variability through time).

Note that in an earlier study, Clausen et al. (1995) performed a detailed geological interpretation "drive-point" contaminant sampling of transects in the NW plume at PGDP. This high quality report resulted in the development of detailed cross sections of TCE and ${ }^{99} \mathrm{Tc}$ in the NW plume in the vicinity of SWMU 7. Similar to Becker et al. (2006), Clausen et al. (2005) indicated that the high RGA TCE concentration spikes might be associated with a local SWMU 7 source, based on the available data.

Importantly, in both of these previous studies, the potential for alternative technical interpretations was highlighted. In evaluating the multiple lines of evidence for this report, key data from Clausen et al. (1995) is brought forward and will be presented below.

\section{Follow-up Studies and Updated Information}

PGDP site personnel completed several activities to address the various recommendations and data gaps. For example, PGDP conducted a review of waste disposal records from the period 1957 and 1979 when material was disposed at SWMU 7. Documented disposals included non-combustible trash, uranium-contaminated concrete pieces, and uranium-contaminated drums. The records did not document substantive disposal of TCE or any other liquid wastes within SWMU 7. The records suggest that TCE, where present, would be limited and result from disposal of other types of waste materials that had contacted, or been contaminated, by solvents. 
Soils and sediments collected beneath and adjacent to SWMU 7 have been characterized as part of a series of site/remedial investigations. TCE concentrations in soil were measured during the Phase I and Phase II SWMU 7 Site Investigation (SI), the Waste Area Group (WAG) 22 Remedial Investigation (RI), the Burial Ground Operable Unit (BGOU) RI, and a drainage ditch characterization program. Figure 5 is a sketch that provides a snapshot of the distribution of locations/sites where soil samples were collected and analyzed for TCE and other solvents. These samples include shallow samples, core samples, and soils collected from angle borings installed beneath former disposal pits/areas. According to the summary reports, the TCE concentrations in the soil samples were low (all samples were below about $0.25 \mathrm{mg} / \mathrm{Kg}$ and $95 \%$ of the samples were below about $0.025 \mathrm{mg} / \mathrm{Kg}$ ). During the 1991 Phase 2 site investigation, test pits were excavated at suspect locations within SWMU 7 (in areas expected to potentially have waste drums present based on geophysical surveys) (see Figure 5). Analytical results from the solid materials that were removed from TP-5 and TP-3 during the site investigation activities revealed very limited TCE contamination, specifically: a) the absence of TCE or daughter products in TP-5 (all samples below detection limits) and b) one sample from TP3 that contained low levels of TCE $(0.007 \mathrm{mg} / \mathrm{kg})$ and detectable anaerobic biodegradation products (including vinyl chloride and cis 1,2 dichloroeoethene). The locations of the soil TCE data are reasonably well distributed throughout SWMU 7 and provide credible data suggesting that significant (large and/or high strength) TCE sources are not common or broadly present throughout the area. The soil data are consistent with the disposal records, and similarly do not eliminate the possibility of small or isolated areas containing TCE contaminated materials. 


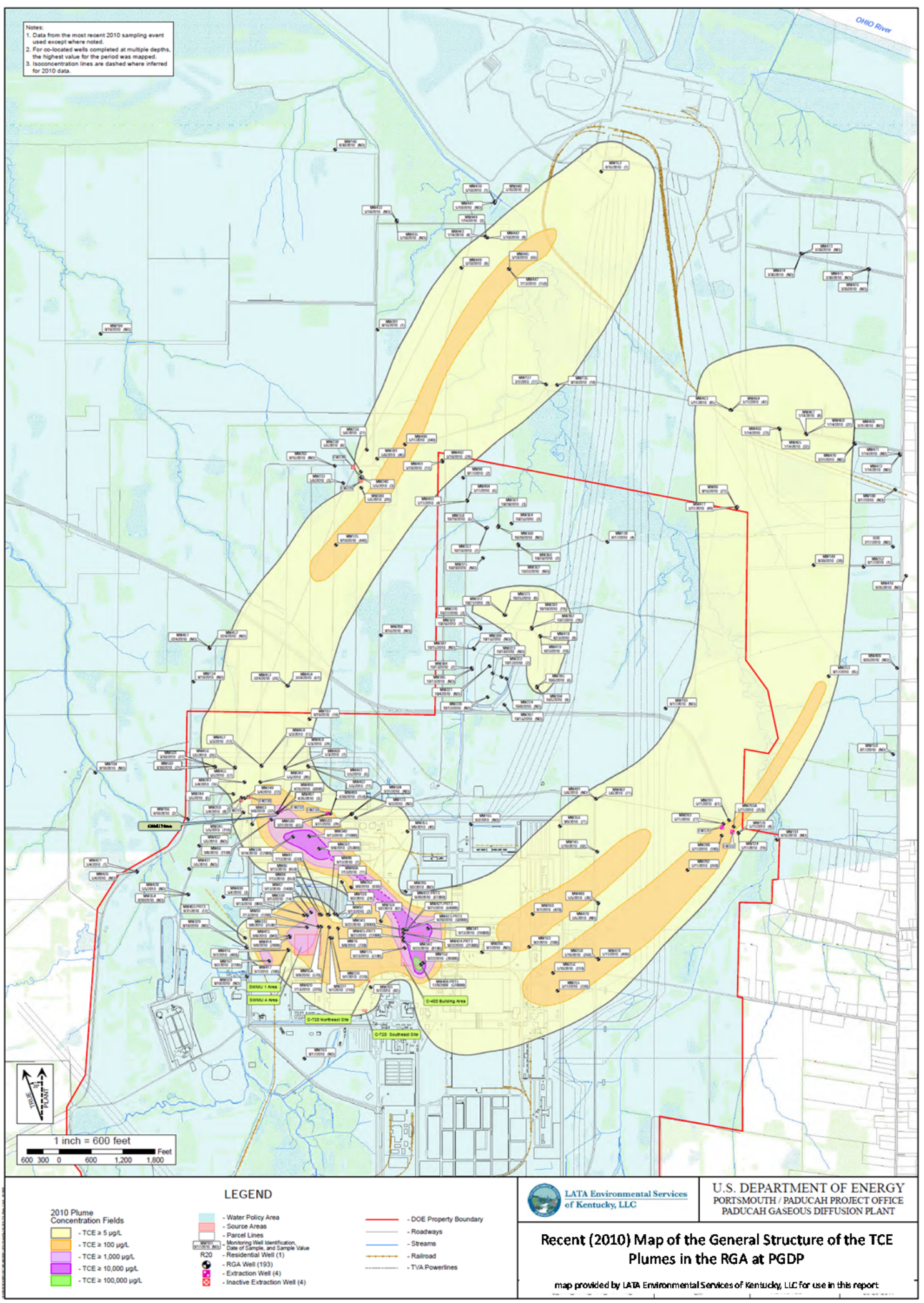

Figure 1. TCE groundwater plumes in the RGA at PGDP 


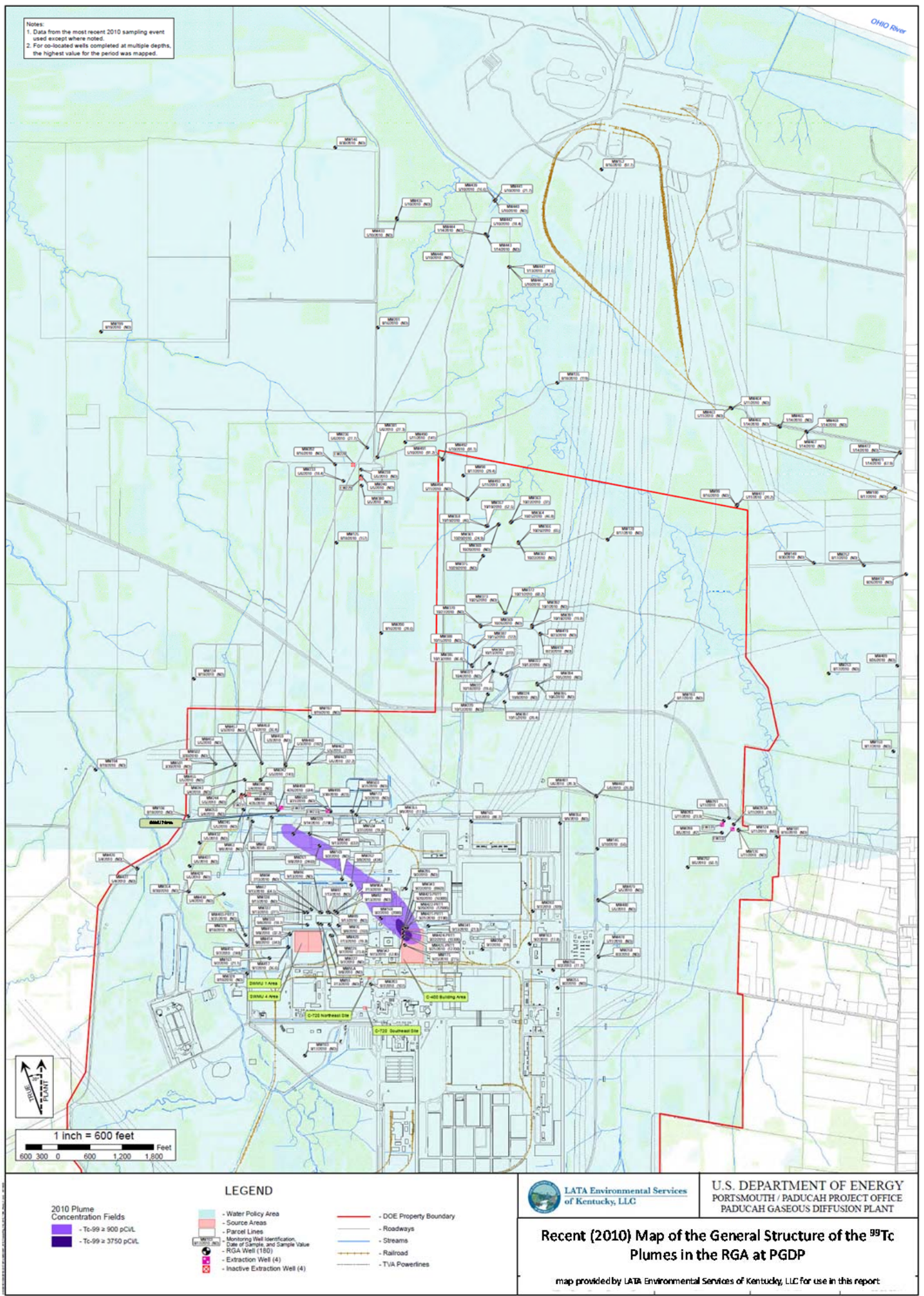

Figure 2. ${ }^{9 y} \mathrm{Tc}$ groundwater plume in the RGA at PGDP 


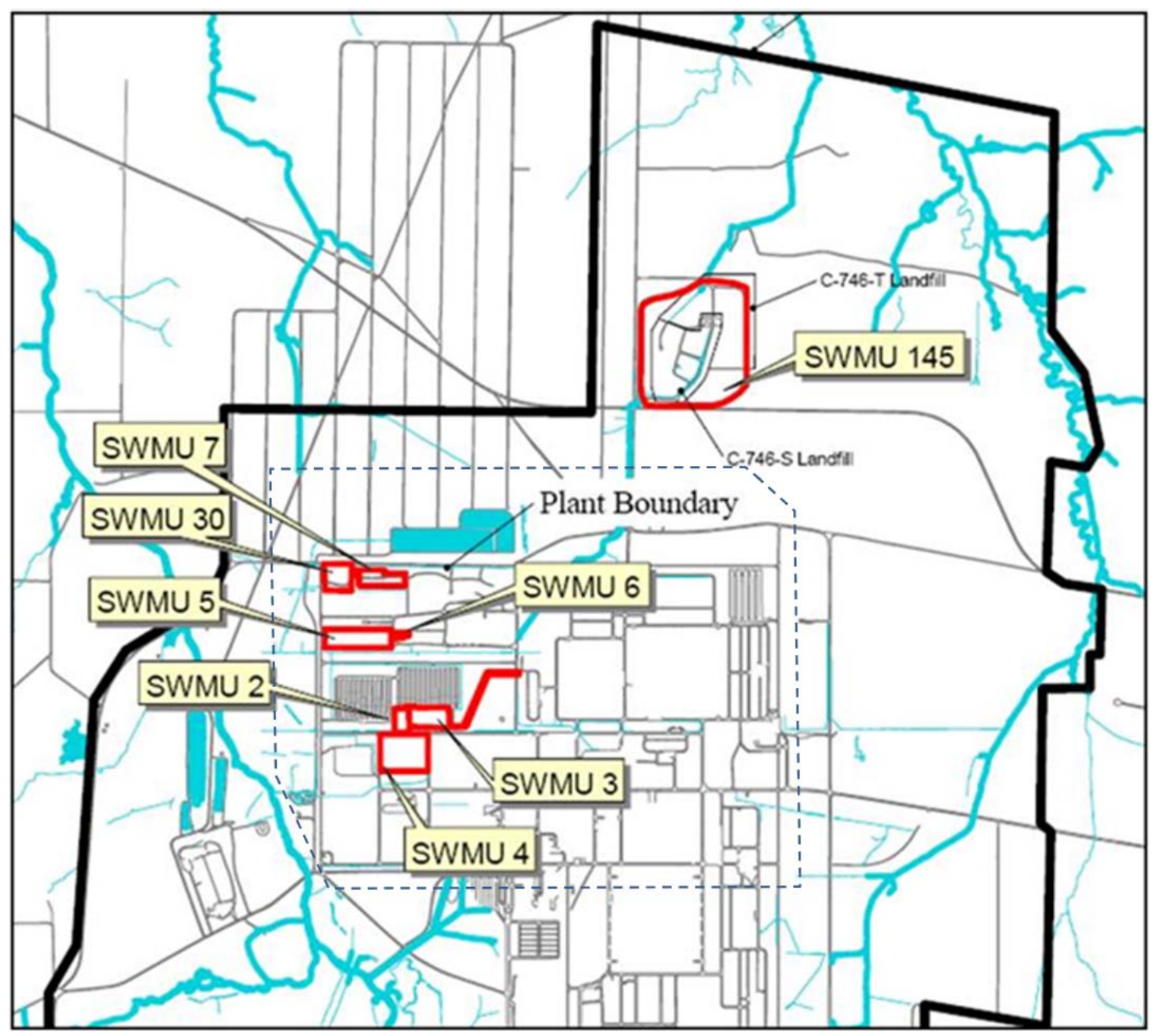

Figure 3. Map location of the various Burial Ground SWMUs at PGDP. (the central PGDP area highlighted Figure 4 is depicted with a dashed outline) 


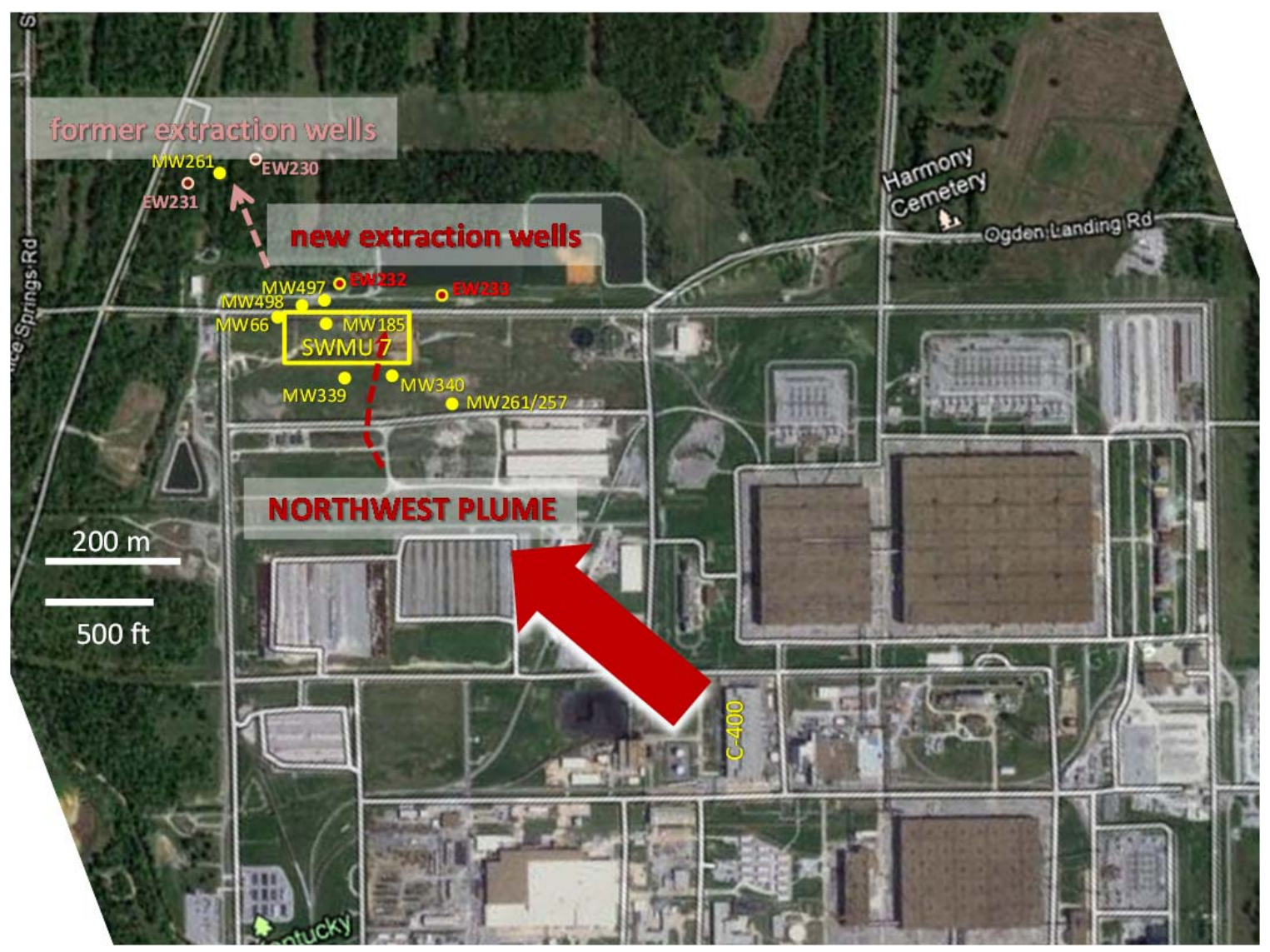

Figure 4. Overhead photograph of a portion of PGDP, annotated to show approximate locations of SWMU 7 and nearby RGA wells.

Large red arrow shows general regional groundwater flow direction. Small dashed arrows show approximate local groundwater flow direction before/after the relocation of extraction well pumping.

Note this figure only shows RGA wells discussed in the text - there are many additional RGA wells within the footprint of this figure. 


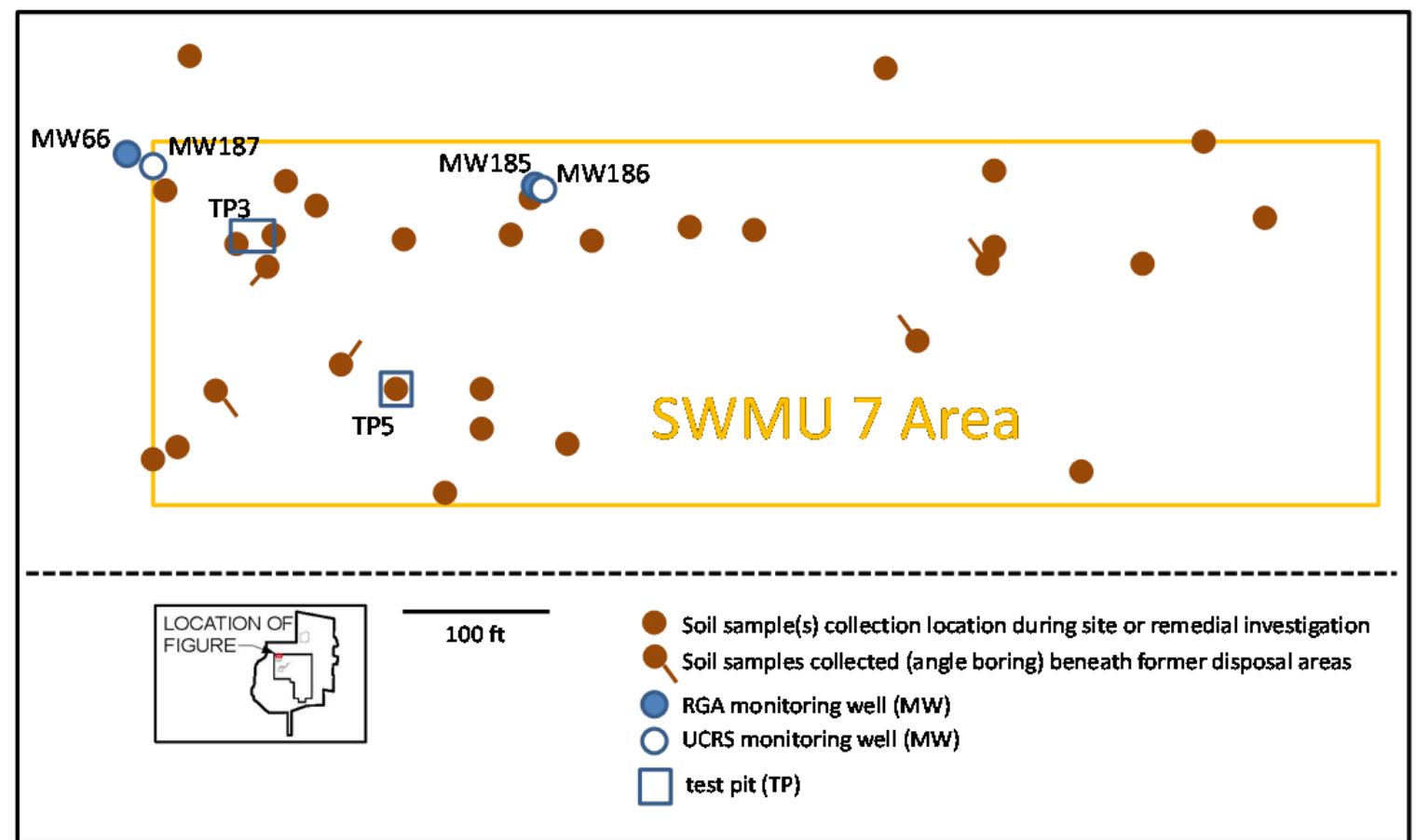

Figure 5. Sketch of soil sample locations in/near SWMU 7

(Includes only those sampling locations where soil was analyzed for TCE and other solvents. Note that the sampling pattern depicted focuses on historical burial pits/layout) 
Since 2006, PGDP personnel have continued to evaluate the groundwater data collected from UCRS and RGA wells in the vicinity of SWMU 7. Elevated TCE concentrations in the MW187 (a UCRS well on the edge of SWMU 7/30 - Figure 5 - with its intake screen significantly above the RGA) has relatively stable TCE concentrations (approximately $2000 \mu \mathrm{g} / \mathrm{L}-$ Figure 6). As discussed in the results section below, this monitoring well is unlikely to be contaminated by the underlying NW Plume in the RGA and the data likely indicate an historical source of TCE from SWMU 7. Based on normal partitioning assumptions, the soil concentration needed to generate a water concentration of 2000 $\mu \mathrm{g} / \mathrm{L}$ would be expected to be in the low $\mathrm{mg} / \mathrm{Kg}$ range (e.g., 1 to $10 \mathrm{mg} / \mathrm{Kg}$ ). TCE concentrations in MW 186 (another UCRS well monitoring the central SWMU 7 area see Figures 5 and 6) were approximately $1000 \mu \mathrm{g} / \mathrm{L}$ in 1991 and have decreased over time. The TCE concentrations measured in UCRS wells in the vicinity of SWMU 7 are all significantly below $1 \%$ of TCE solubility $(10,000 \mu \mathrm{g} / \mathrm{L})$ and are generally below levels that would suggest to a strong proximate TCE source. Continued evaluation of the concentration trends/dynamics of RGA wells in the vicinity of SWMU 7 (Figure 6) indicated the following:

- TCE concentrations in RGA MW-66 continue to oscillate but have not exceeded $10,000 \mu \mathrm{g} / \mathrm{L}$ since 2002 - the peak concentrations have been stable or in decline.

- TCE concentrations in the RGA NW Plume are nominally higher upgradient of SWMU 7 (e.g. in MW339 or MW340) than downgradient of SWMU 7 (e.g., in MW 497 or MW498). The peak concentrations in MW66 (installed beneath SWMU 7/30) generally fall between the concentrations in the upgradient and downgradient wells. This spatial pattern suggests that SWMU 7 is not contributing detectable levels of TCE to the NW Plume.

- The NW plume trajectory appears to have shifted eastward since 2005 reflecting, in part, the dynamic conditions at an operating industrial site with ongoing cleanup and reconfiguration activities. This shift appears to have accelerated after 2010 in response to the relocation of NW Plume extraction wells in late August 2010 (Figure 4); for example, the data indicate sharp decrease in TCE concentrations in MW339 and concomitant increase in MW340 over the past two years. 


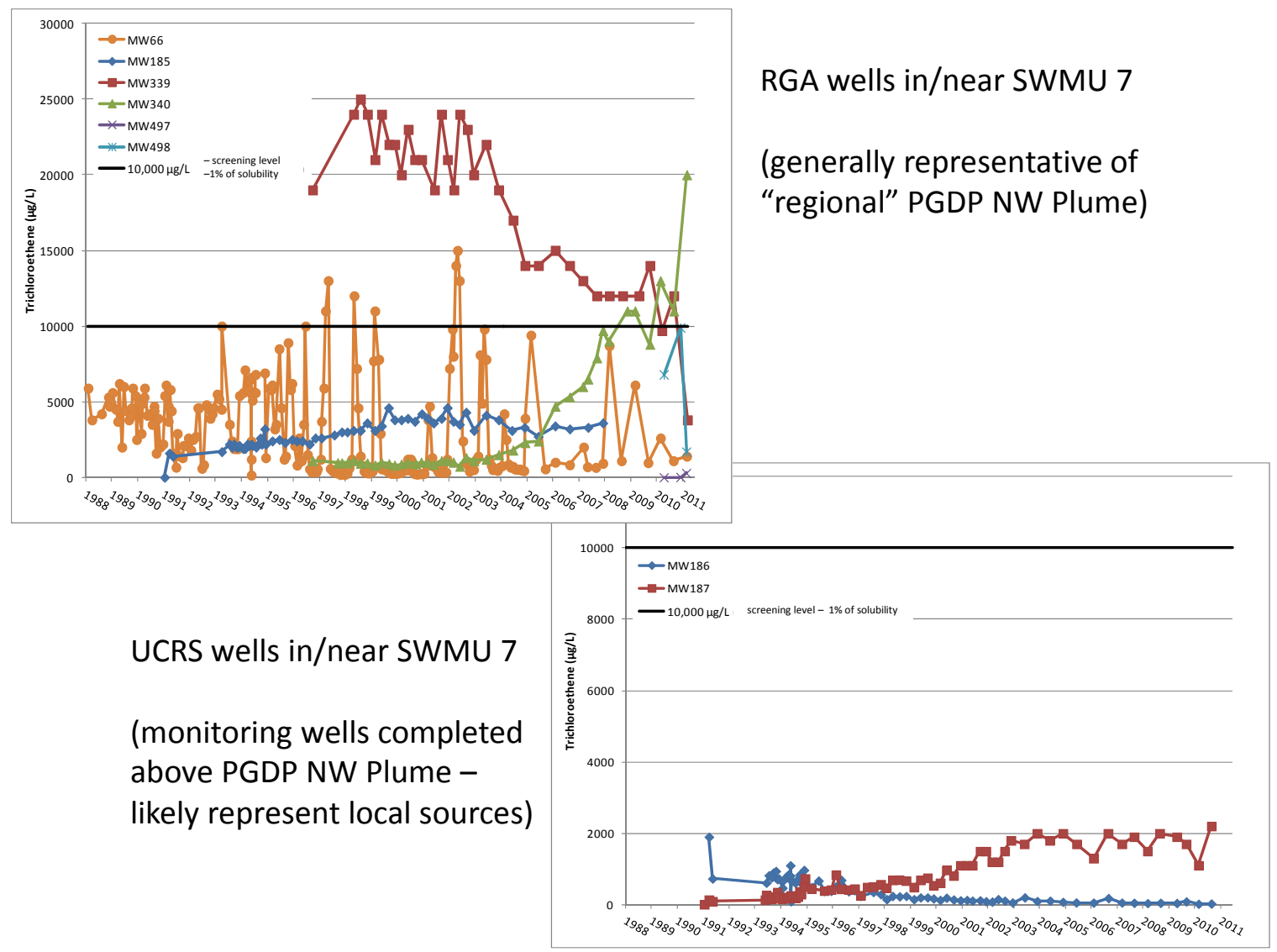

Figure 6. Groundwater trends in select monitoring wells in/near SWMU 7 (Note y-axis units: 0 to $30,000 \mu \mathrm{g} / \mathrm{L}$ for RGA wells and $0-12,000 \mu \mathrm{g} / \mathrm{L}$ for UCRS wells) 


\subsection{Technical Evaluation}

\section{Approach}

The existing historical and field characterization information provide sufficient support to reasonably update the evaluation of the potential for significant TCE sources within SWMU 7. Our efforts in this report were focused on extending the conceptualization of the site by examining temporal and spatial patterns in the groundwater data and the associated relationships between the key contaminants (TCE and ${ }^{99} \mathrm{Tc}$ ).

In order to do this, the available contaminant and water level data for selected wells in the vicinity of SWMU 7 were extracted from the online Paducah/Portsmouth environmental groundwater database using queries. Additional information was provided by the Kentucky Research Consortium for Energy and Environment (KRCEE). We commend the PGDP team and KRCEE for the quality of the technical efforts in collecting and organizing the data, and in maintaining and providing a usable web-based graphical interface (allowing queries of laboratory and field results, generation of maps, and providing well construction information, etc.). For our analysis, the database was queried, and the data were tabulated as a function of well/parameter/time for TCE, ${ }^{99} \mathrm{Tc}$, and water level. The data were screened to remove the few non-representative values data for almost all of the sampling events were retained for the follow-on analysis. The screening removed the perturbed data collected during active pumping and field tests, and removed data that were outliers compared to the historical record and adjacent values (e.g., values that were off by a significant multiple). For a sampling event that generated replicate samples in a well, a median value of the available data was used. To calculate TCE $/{ }^{99}$ Tc ratio, the temporal data were aligned and dates in which only one of the contaminants were analyzed were eliminated. The remaining data were tabulated and used in the analysis. For example, in MW66 the remaining 230 sampling events beginning in 1988 were tabulated; MW339/340 generated 32 and 38 sampling events, respectively, beginning in 1996. The local rainfall data was provided by KRCEE and the official statewide record of monthly rainfall data from 1895 to present for Kentucky was downloaded from the state climatological database for comparison. These detailed tabulations provide a robust historical record that provides insight into the dynamic groundwater system at PGDP.

\section{Refined Conceptual Model for the RGA in the Central PGDP Area - "A Hypothesis"}

The well screen in MW66 is in the uppermost portion of the RGA and this positioning was cited in Becker et al. (2006) as a primary basis for suggesting that the peak (high) concentrations in MW66 may have a local source. An alternative conceptual model is depicted in Figure 7. In this figure, a long-section (long-sect) of wells in the NW Plume in the vicinity of SWMU 7 is shown in the lower panel. For each well, the approximate vertical screen location has been normalized (elevation above mean sea level, msl) and is depicted as a bold line. The wells are roughly arranged from upgradient to downgradient (not to scale) to aid in developing a larger scale hydrogeological conceptual framework/hypothesis. 
The upper panel in Figure 7 is a simplified long-sect of key features of the subregional (PGDP scale) hydrogeology. In this panel, a major TCE source (e.g., the Building C-400 Area) is depicted on the left with groundwater flow in the lower unit (the "RGA NW Plume") shown from left to right. Along the groundwater flow path, infiltration through the uncontaminated upper ("UCRS") zone would add a thickening layer of "clean" water to the uppermost RGA. The geometry of this layer can be calculated (e.g., Looney and Paquette, 2000) as a function of the relative rates of vertical infiltration through the UCRS (a low rate) to horizontal flow in the RGA (a high rate), yielding a thin wedge for the PGDP scenario. In the real world, infiltration is non-uniform and varies both temporally and spatially. Infiltration is a function of weather patterns, and can be particularly patchy in active industrialized facilities that have large buildings, covered areas, ponds and lagoons, potential for leaking water/sewer lines and large cooling systems, and periodic reconfiguration activities. Moreover, the horizontal flow in the RGA can vary over time in response to the amount and location(s) of infiltrating water. For example, if significantly more (or less) water infiltrates upgradient of a particular location in the RGA, the horizontal flow through the aquifer would increase (or decrease) and the wedge of "clean" water at that location would thin (or thicken). This is shown in the lower panel as an oscillating arrow representing the upper boundary of the most highly contaminated portion of the NW Plume. Note that the "clean water" would contain relatively low concentrations of TCE (from mixing and diffusion).

The assessment in Becker et al. (2006) presumed that the well screen in MW66 was located fully in the "clean" wedge of upper RGA and that the high concentration spikes resulted from pulses of contaminated groundwater entering from above (shown as a downward arrow from the UCRS in the lower panel). An alternative hypothesis is that the MW66 well screen is located near the oscillating NW Plume upper boundary and that the normal oscillations of this boundary in response to temporal hydrogeologic conditions result in the observed MW66 concentration spikes. Examination of multiple lines of evidence, such as the co-contaminant ratios and responses of TCE concentration to known hydrologic modifications (such as shifting the location of NW Plume extraction wells) can assist in determining the relative likelihood of the alternative hypotheses. Note that UCRS monitoring wells MW 186 and MW187 (located in/near SWMU 7) are also shown on the lower panel -the screens/intakes for these wells are significantly above the UCRS-RGA interface (approximately 8 to $10 \mathrm{~m}$ ).

In an earlier study, Clausen et al. (1995) collected detailed depth discrete contaminant and geological information at a number of transects in the NW Plume. Transect A-A', in the vicinity of SWMU7 (Figure 8) was similar to the other transects, showing significant contaminant levels in the RGA. The elevated contaminants in all of the various transects, including A-A', align with the expected location of the plume core. Notably, in A-A' in the vicinity of MW66, the TCE concentrations were highest in the lower RGA while the 99Tc was high in the middle and lower RGA. This distribution could result from a number of factors (e.g., TCE dense nonaqueous phase liquid behavior at the upgradient source combined with hydrologic controls), but the pattern is consistent with the conceptual model depicted above (and with the contaminant ratios discussed in the next 
section). As with the other lines of evidence discussed in this report, these historical cross sections alone do not support a definitive interpretation. Clausen and his colleagues indicated that the data indicated the potential for a significant SWMU 7 source. In the sections below we add additional lines of evidence to help resolve this question.

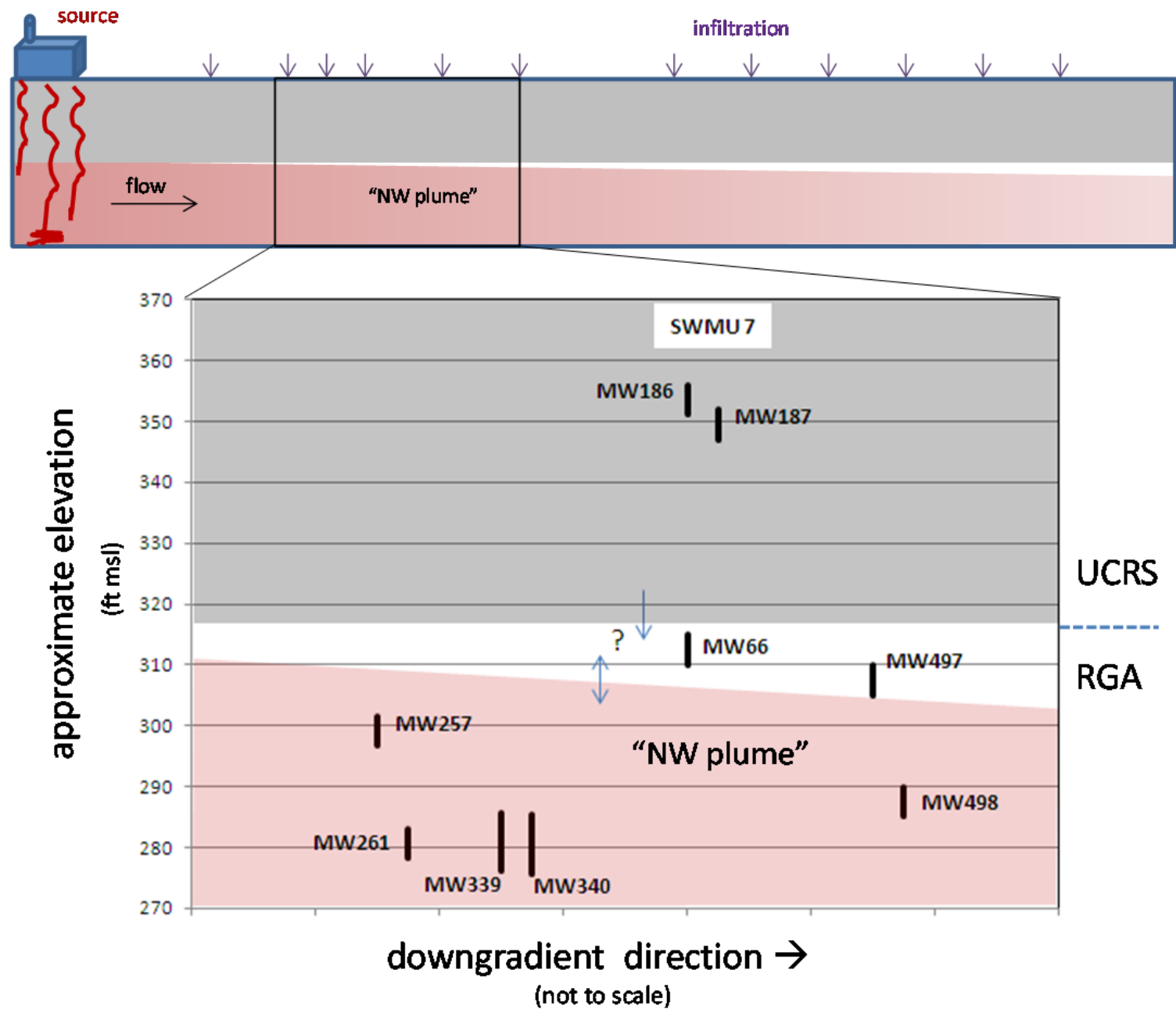

Figure 7. Sketch of hypothetical plume geometry for a central PGDP scenario 

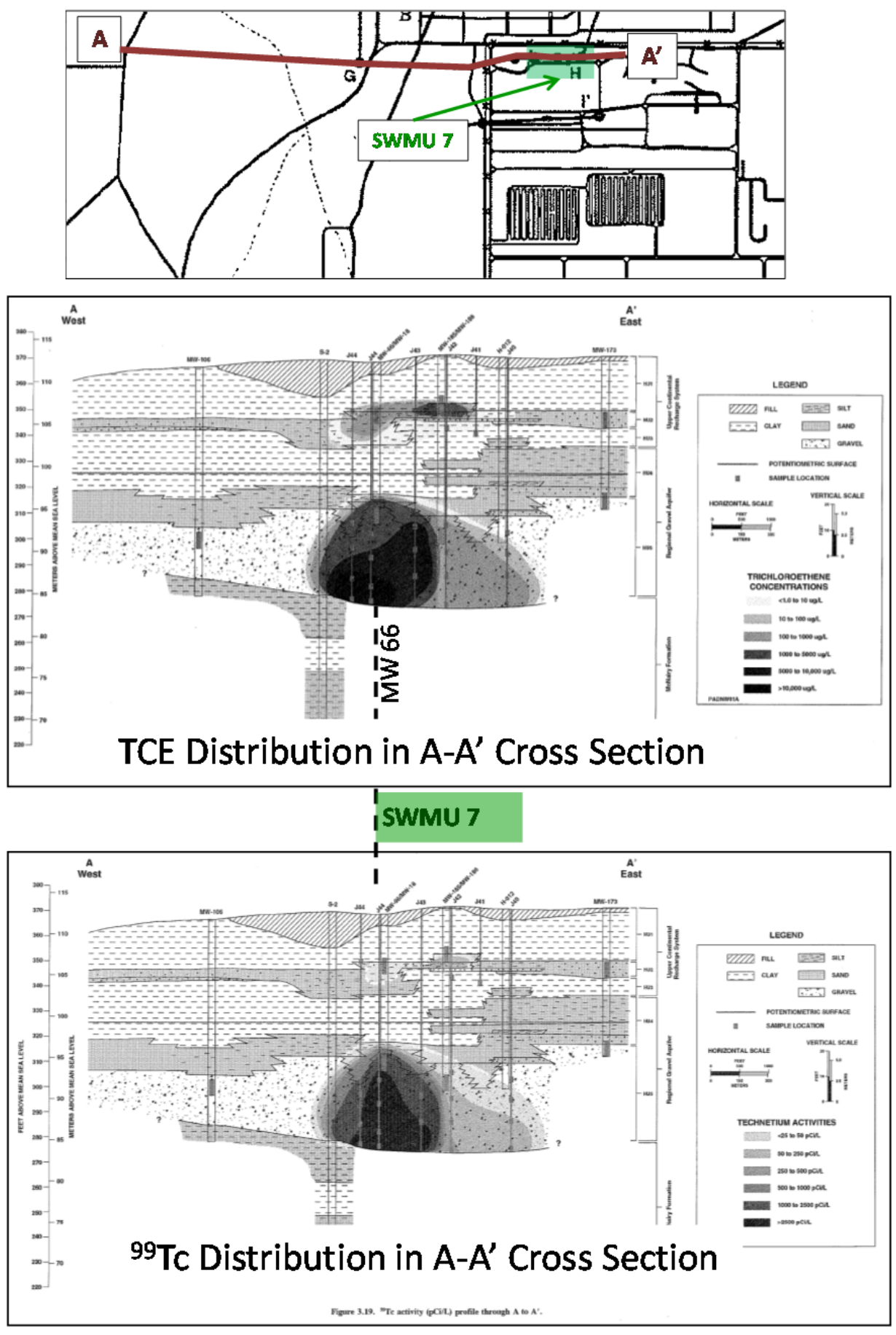

Figure 8. Cross sectional contaminant distributions in the UCRS and RGA in the vicinity of SWMU 7 (from Clausen et al. 1995) 


\section{Results}

Figure 9a documents the oscillating concentrations in MW66 and provides temporally registered graphs for TCE, ${ }^{99} \mathrm{Tc}$, and groundwater head (elevation). The data show a clear correlation. Periods of high groundwater head (above about $326 \mathrm{ft} \mathrm{msl}$ ) are generally coincident with high concentration of TCE and higher activity of ${ }^{99} \mathrm{Tc}$. The identification of a specific groundwater head that could be associated with the two states (high concentrations versus low concentration) suggests a second version of this figure in which we include the groundwater head (elevation) in nearby UCRS wells to determine if the data supported a specific change in the UCRS-RGA boundary conditions or even a temporal reversal of flow direction. Figure $9 \mathrm{~b}$ adds the groundwater head measured in MW187 to the graph of MW66 head. Note that the groundwater head in MW187 is relatively stable, and is about $40 \mathrm{ft}(>10 \mathrm{~m})$ higher than the head in MW66. Thus, the measured groundwater elevations at the site do not support a hypothesis that the oscillations in measured head in the RGA would impact the vertical driving force for migration from above and result in peaks from local TCE or ${ }^{99}$ Tc sources. More specifically, the head difference is lowest during periods in which the RGA head is the highest (this would correlate with relatively less flow from above during the times when the peaks are observed) and the measured difference between MW187 and MW66 ranges from 30 to 45 feet (about 10 to $15 \mathrm{~m}$ ), and shows that a temporal head reversal is not present; instead, the expected downward flux of water from the UCRS in this area would be expected to be relatively consistent and change in magnitude by $\pm 15 \%$ or so over time.

A second line of evidence - co-contaminant ratios - is explored in Figure 10. This figure documents the oscillating concentrations in MW66, and provides temporally registered graphs for TCE, ${ }^{99} \mathrm{Tc}$ and $\mathrm{TCE} /{ }^{99} \mathrm{Tc}$ ratio. The peaks in $\mathrm{TCE} /{ }^{99} \mathrm{Tc}$ ratio correspond with the peak concentrations, and the peak ratio values in MW66 range from 4 to 6.5 . The peak ratios in MW66 correspond closely to the measured ratios in upgradient wells in the NW Plume. For example, moving from upgradient toward SWMU 7, the median $\mathrm{TCE} /{ }^{99} \mathrm{Tc}$ ratio in MW261 over the period of record is 7.8 and the median $\mathrm{TCE} /{ }^{99} \mathrm{Tc}$ ratio in MW339 over the period of record is 6.6. These TCE $/{ }^{99} \mathrm{Tc}$ ratios are consistent with those presented in earlier PGDP reports (by Claussen et al. (1997), others who attribute the spatial patterns in ratios to potential attenuation of TCE relative to the long lived $\left.{ }^{99} \mathrm{Tc}\right)$. The highest ratios measured in MW66 correspond closely to the ratios measured in the nearest upgradient location (MW339). The data indicate that the chemistry of MW66 most closely resembles the upgradient plume during periods in which the hydrologic conditions have fully developed. Note that the TCE $/{ }^{99} \mathrm{Tc}$ ratio in MW187 (TCE contaminated UCRS well in SWMU 7) is $>1000$ and the measured TCE concentration in MW187 is significantly below the peak concentrations observed in MW66. The horizontal and vertical pattern of co-contaminant ratios and contaminant concentrations provides another line of evidence supporting the linkage of the peaks in MW66 to the regional NW Plume rather than resulting from vertical transport from SWMU 7. Note that co-contaminant ratios should be used with caution because the history/locations of disposals are not fully known and are unlikely to correlate precisely, and the transport behaviors of the contaminants may not be identical - the approach is quite useful in combination with other lines of evidence. 


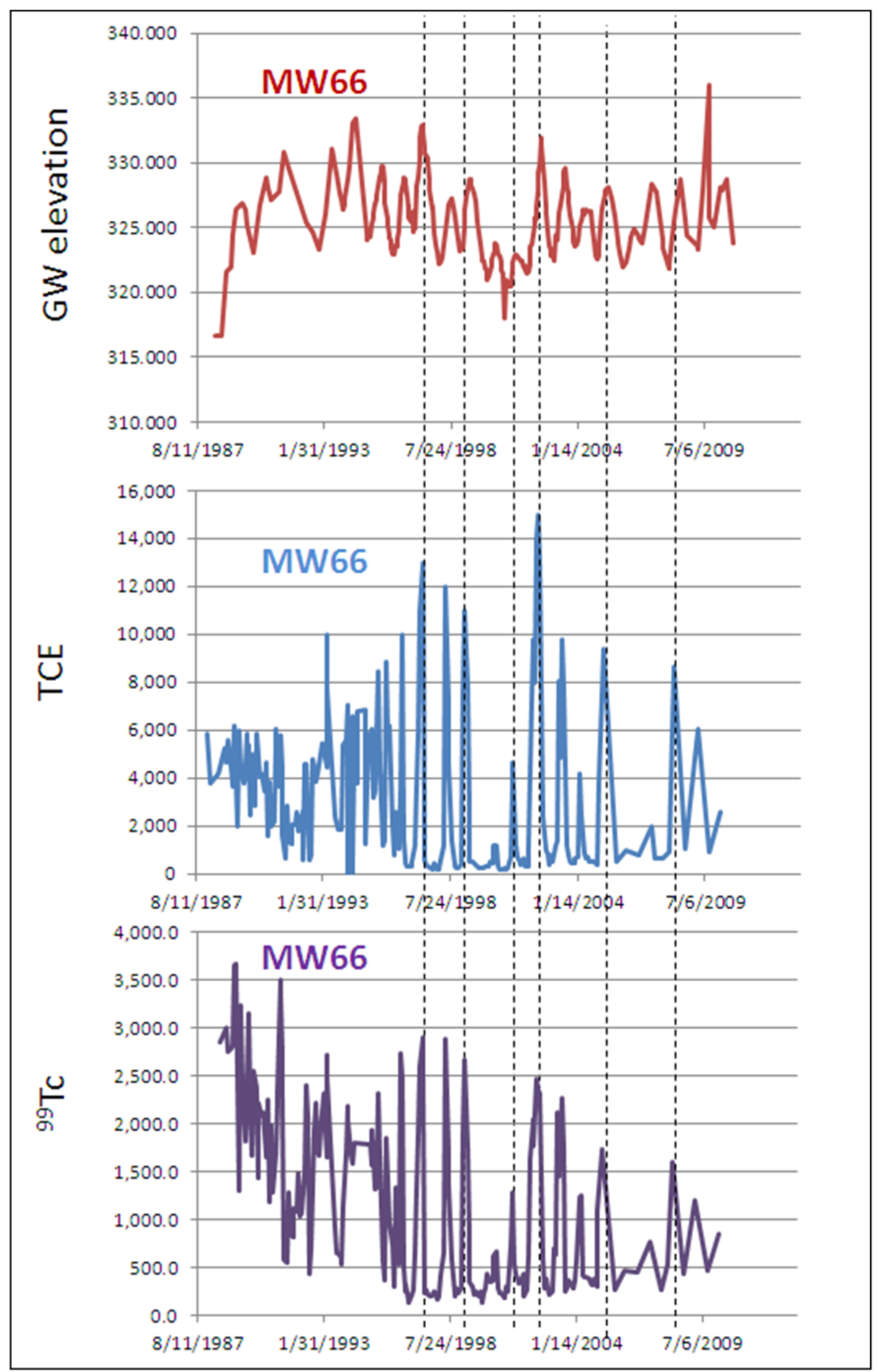

Figure 9a. Temporally registered data: RGA head - TCE $-{ }^{99} \mathrm{Tc}$ in MW66 (units: Head in $\mathrm{ft} \mathrm{msl}$, TCE in $\mu \mathrm{g} / \mathrm{L},{ }^{99} \mathrm{Tc}$ in $\mathrm{pCi} / \mathrm{L}$ ) 


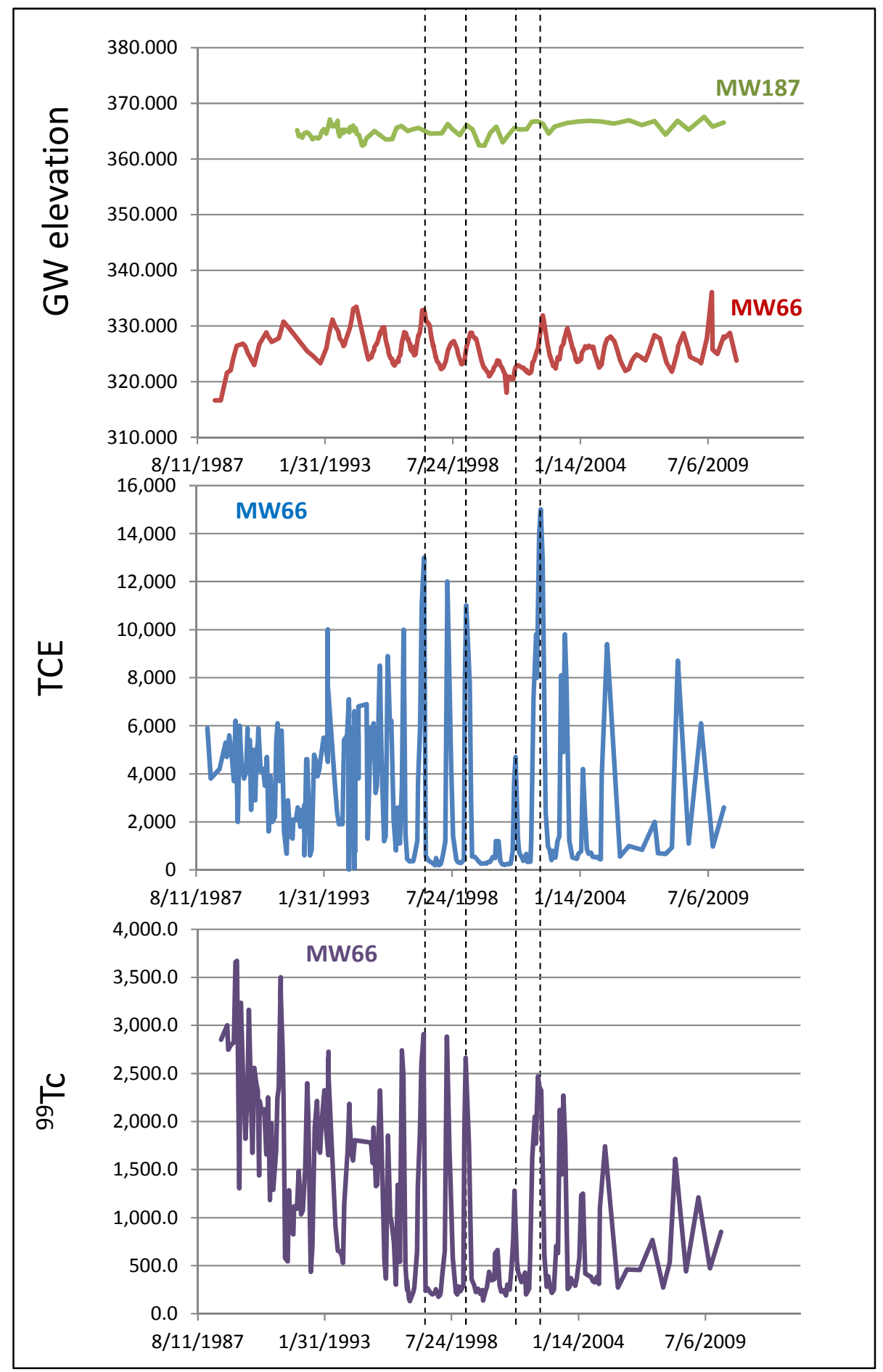

Figure 9b. Temporally registered data: RGA head - TCE - ${ }^{99} \mathrm{Tc}$ in MW66 - UCRS head in MW187 (units: Head in $\mathrm{ft} \mathrm{msl}$, TCE in $\mu \mathrm{g} / \mathrm{L},{ }^{99} \mathrm{Tc}$ in $\mathrm{pCi} / \mathrm{L}$ ) 


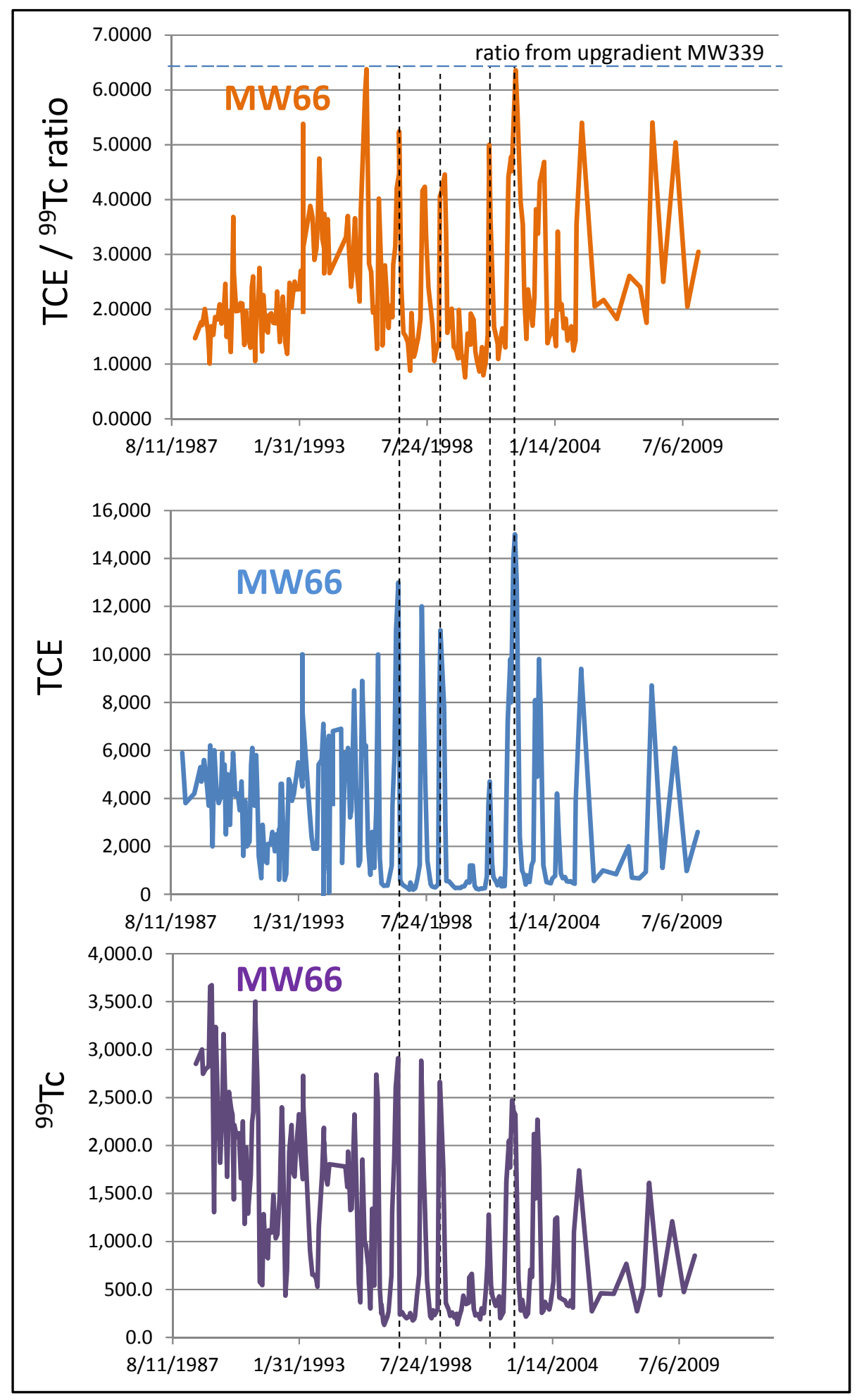

Figure 10. Temporally registered data: $\mathrm{TCE} /{ }^{99} \mathrm{TC}$ ratio $-\mathrm{TCE}-{ }^{99} \mathrm{Tc}$ in MW66 (units: TCE in $\mu \mathrm{g} / \mathrm{L},{ }^{99} \mathrm{Tc}$ in $\mathrm{pCi} / \mathrm{L}$ ) 
Figure 11 attempts to relate the oscillations in concentration in MW66 to external hydrologic boundary conditions/forcing factors. In this figure, we document the oscillating concentrations in MW66 using temporally registered graphs for groundwater head (elevation), TCE, and monthly rainfall. The monthly rainfall data (data symbols) are highly variable and the raw line graph was difficult to interpret - a smoothed line that represents a simple 2 month moving average is presented on the graph. There is a loose correspondence between the peaks in rainfall and the peaks in groundwater elevation and concentration spikes. This supports hypotheses that relate the observed concentration oscillations to hydrologic controls and suggests that periods of higher rainfall result in increased infiltration that influences both groundwater head and the trajectory of contaminant plume migration. Note that in a highly permeable aquifer like the RGA, small changes in pressure (head) gradients result in significant changes in flow. Thus, an overall change in head of 5 or $10 \mathrm{ft}$ (1.5 to $3 \mathrm{~m})$ in the central PGDP area represents a substantial change in the total water moving regionally through the system toward a distal boundary. Conversely, these large regional-scale changes may not be strongly reflected in local horizontal gradients (due to the gradient-flow relationship described above). We were not successful in relating temporal horizontal gradients (calculated between any the wells analyzed) to the temporal concentration oscillations or to overall temporal groundwater head variations.

Figure 12 provides supplementary information about the potential sources of anthropogenic water inputs in the vicinity of SWMU7 (Walt Richards and Steve Hampson, personal communication). In this figure, the C-400 Building and SWMU7 are labeled and potential water inputs are shaded blue. The potential sources include the Recirculating Cooling Water (RCW) facilities and areas of frequently standing or ponded water. Of these, the RCW facilities are notable because they are known to release large amounts of water to the surrounding environment. Since the water is not contaminated, the reconfiguration and repair of leaks is performed on an ad hoc basis. Since no detailed records are available related to the quantities and timing of anthropogenic water sources, no temporal graph can be generated. Currently KRCEE is evaluating the physical and chemical measurements in the groundwater database and they are finding that the RGA flowing under the site has exhibited statistically elevated temperatures for many years (Steve Hampson, personal communication). These data suggest that the RCW systems may be a major contributor of water to the subsurface. Our screening evaluation of the information suggests that anthropogenic water may play a substantive role in the dynamics of plumes in the RGA and as such, these water sources may warrant explicit consideration in future environmental/plume management strategies. 


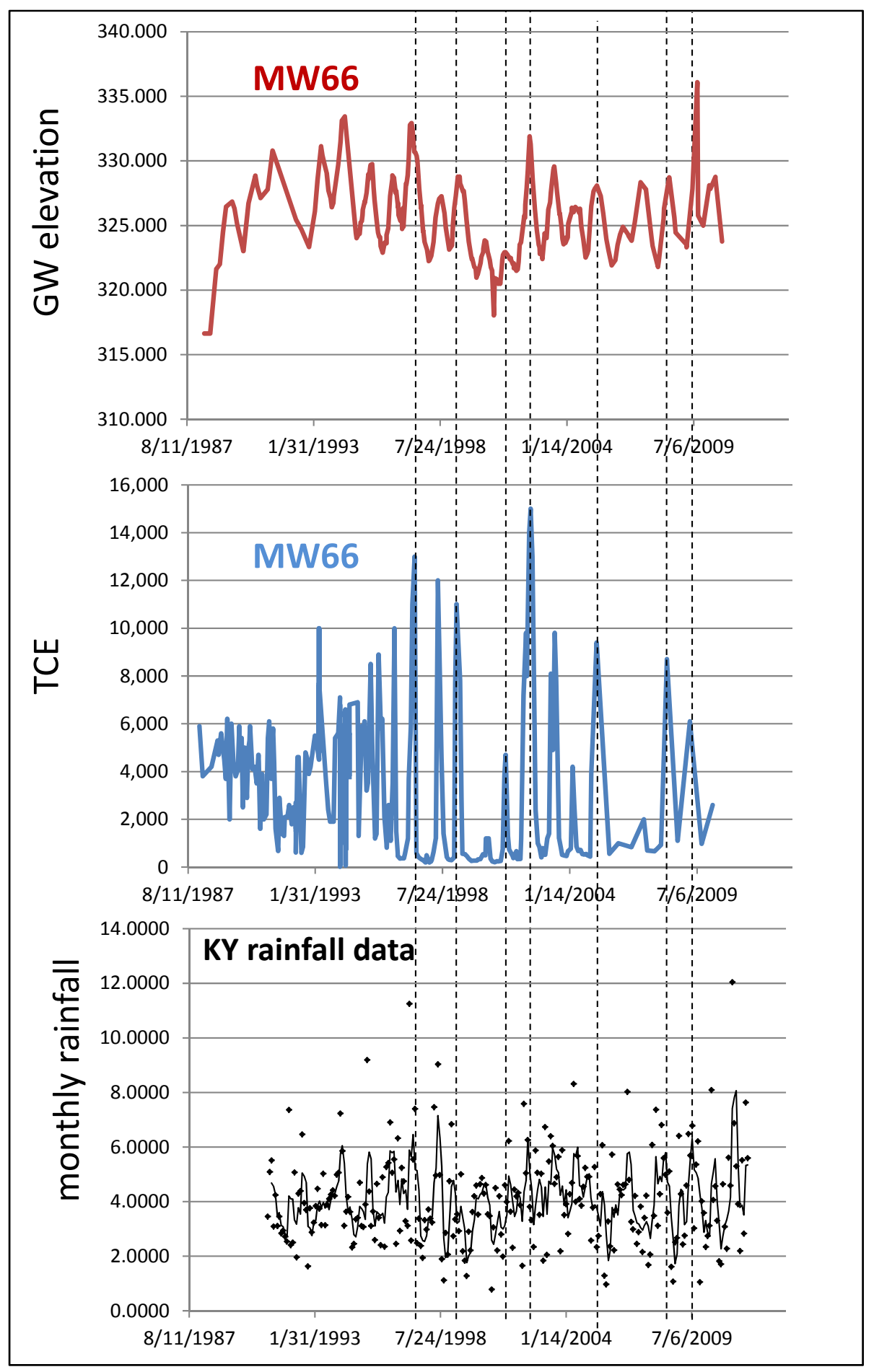

Figure 11. Temporally registered data: RGA head - TCE in MW66 - monthly rainfall (units: Head in $\mathrm{ft} \mathrm{msl}$, TCE in $\mu \mathrm{g} / \mathrm{L}$, monthly rainfall in inches - rainfall line is a 2 month moving average) 


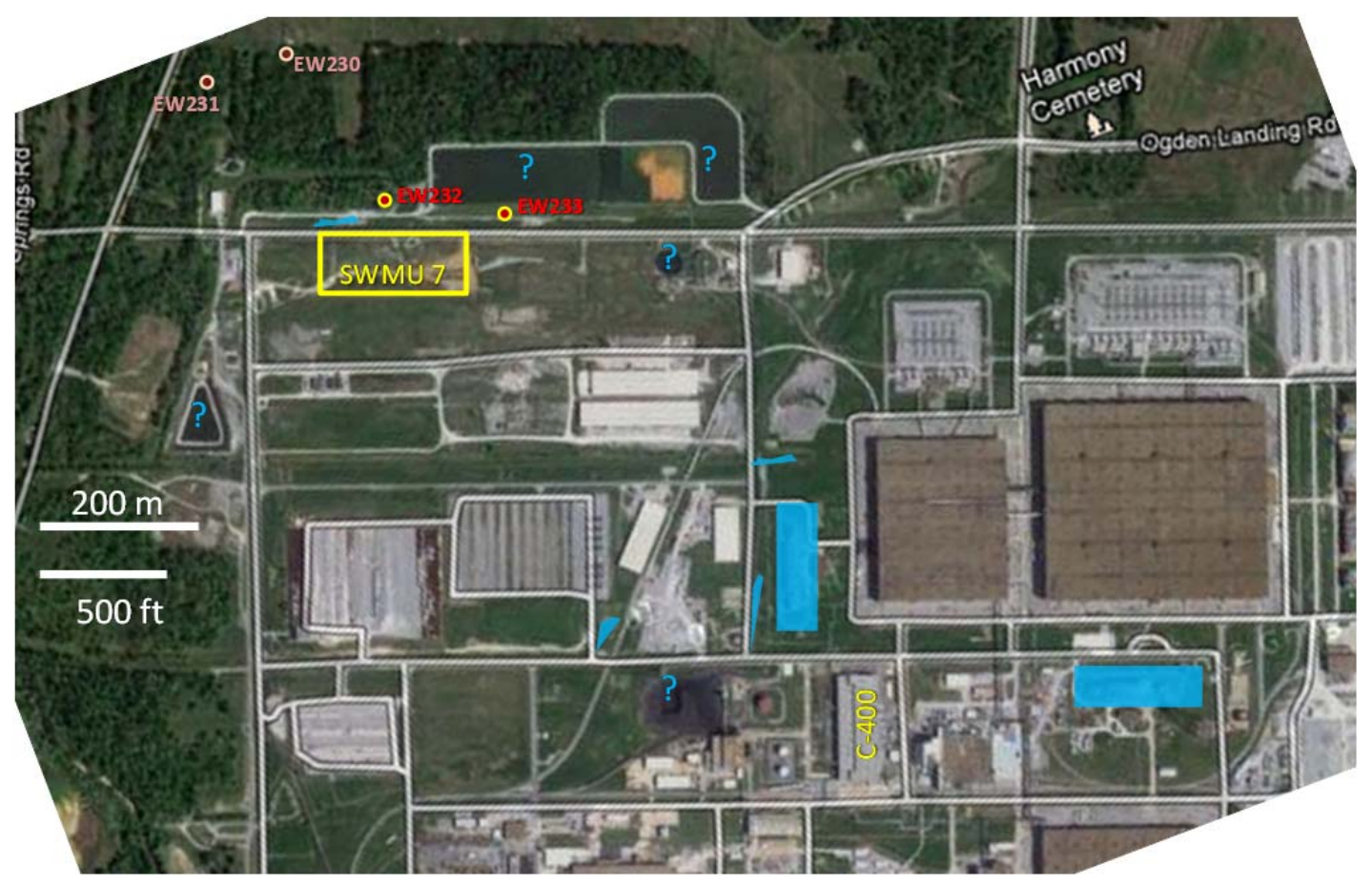

Figure 12. Overhead photograph of central PGDP annotated to show C-400 Area and SWMU 7 and known areas of anthropogenic water releases or of frequently standing water

(The rectangles are the large RCW systems)

The overall behaviors of TCE contamination in groundwater from the wells (Figure 6) are consistent with the conceptual model in (Figure 7). Most importantly, wells in the middle to lower RGA provide relatively consistent concentrations with concentration trends that respond as expected to hydrologic changes such as changing the locations of the NW Plume extraction wells in late 2009. The significant decrease in MW339 and in MW 498 after this major change suggests that these wells are near the lateral edge of the NW Plume. The oscillation of concentration of TCE in MW66 suggests that it is in a location that extracts/samples distinct and different water sources depending on the controlling hydrogeologic conditions. Also, notable for MW66 is that no significant concentration peaks have been observed in this well during the period after the extraction well locations were moved. While it is too early to develop a definitive conclusion, this lack of recent concentration oscillation may be another indicator suggesting: a) peak concentrations in MW66 are linked to the regional NW Plume, b) an eastward shifting of the plume in the vicinity of SWMU 7 toward the new extraction well locations, and c) the magnitude of future concentration oscillations in MW66, if observed, will be damped. 


\subsection{Conclusions and Recommendations}

Evaluation of SWMU 7 disposal records, SWMU 7 soil data, and related spatial and temporal groundwater data indicate that the peak concentrations measured in MW66 are associated with, and representative of, the regional PGDP NW Plume. This conclusion based on "multiple lines of evidence" is generally consistent with assessments by PGDP personnel, and is supported by the extended groundwater interpretation presented herein - specifically, the magnitude of the concentrations for both TCE and ${ }^{99} \mathrm{Tc}$, concentration and groundwater head relationships, TCE $/{ }^{99} \mathrm{Tc}$ ratios, and responses of the system to changes in extraction well pumping. All of these factors can be related to a relatively simple conceptual model in which the contaminant plume(s) would be expected to respond to complicated site conditions in predictable ways. This type of conceptualization bounds the expected system behavior and supports development of environmental cleanup strategies, providing a basis to support decisions even if it is not feasible to completely characterize or understand all of the myriad spatiotemporal factors and boundary conditions controlling the transport of contaminants in the groundwater.

Our conclusion that the peak concentrations in MW66 are linked to the regional PGDP NW Plume does not imply that TCE is not present in SWMU 7. The available soil and groundwater data (e.g., MW187) indicate that the some of the wastes disposed in this facility contacted and/or were contaminated by TCE. In our assessment, the relatively small amount of TCE associated with SWMU 7 is not contributing detectable TCE to the groundwater, and therefore does not represent a significant threat to the surrounding environment, particularly in an area where remediation and/or management of TCE in the NW plume will be needed for an extended timeframe. If required, additional characterization to better define the presence, quantity and location of potential TCE sources in SWMU 7 could be performed. A variety of technologies are available including: a) soil gas surveys or sorbent traps such as GORESorbers ${ }^{\mathrm{TM}}$ installed below the surficial materials, b) soil gas profiling using a GeoProbe ${ }^{\mathrm{TM}}$ or cone penetrometer, c) small SVE tests to sample moderate size areas, and others. Similarly, if required, actions to address the limited quantities of TCE in SWMU 7 might include a number of options that would not involve the cost or risk of waste excavation-handling-disposal - these options include soil vapor extraction and innovative treatments to limit future flux at the UCRS-RGA interface (e.g., neat oils). These remediation technologies are presented and discussed Looney et al. (2011).

With regard to groundwater monitoring, we recommend continued sampling of the monitoring wells, and incorporation of the refined conceptual model into future interpretations of groundwater concentration trends and spatial patterns. Equally important, we recommend that the site consider the potential impacts to groundwater and the contaminant plumes as they plan onsite operations, remediation and reconfiguration activities. For example, this conceptual model suggests that rerouting drainage water, constructing ponds or basins, reconfiguring cooling water systems, capping sites, decommissioning buildings, fixing (or not fixing) water leaks, and other similar actions will potentially have a "direct" impact on the groundwater plumes. 


\subsection{References}

Becker, D., L. Lien, R. Greenwald, B. Looney and B. Moore, 2006. Review Report: Groundwater Remedial System Performance Optimization, Paducah Operations, U.S. DOE Office of Environmental Management, Washington DC.

Claussen, J.L., J.L. Zutman, D.A. Pickering, and N.D. Farrow, 1995. Final Report on Drive Point Profiling of the Northwest Plume and Analysis of Related Data. Document No. KY/ER-66, U.S. Department of Energy, Paducah Portsmouth Project Office, Lexington $\mathrm{KY}$.

Clausen, J. L., N.C. Sturchio, L.J. Heraty, L. Huang, and T. Abrajano, 1997. Evaluation of Natural Attenuation Processes for TCE and Tc-99 in the Northwest and Northeast Plumes Plume at the Paducah Gaseous Diffusion Plant Paducah, Kentucky, Document No. KY/EM-113, U.S. Department of Energy, Paducah Portsmouth Project Office, Lexington KY.

Looney B.B., J. Rossabi, M.B. Amidon, L. Stewart and C.A. Eddy-Dilek, 2011. Independent Technical Review of the Focused Feasibility Study and Proposed Plan for Designated Solid Waste Management Units Contributing to the Southwest Groundwater Plume at the Paducah Gaseous Diffusion Plant, SRNL-STI-2011-00290, DOE Office of Scientific and Technical Information, Oak Ridge TN (www.osti.gov).

Looney, B.B. and D. E. Paquette, 2000. Tritium Source Characterization and the High Flux Beam Reactor, Brookhaven National Laboratory, in Vadose Zone Science and Technology Solutions, B.B Looney and R.W. Falta eds., Battelle Press, Columbus OH. 